\title{
Why do the Nails and Hair of Patients Infected with Coronavirus Fluoresce Under Wood's Lamp?
}

\author{
Nazik $H^{1 *}$, Enes Güner $\mathbf{M}^{1}$, Nazik $S^{2}$, Gümüşer $F^{2}$, Öztürk P $^{1}$, Kamil Mülayim $\mathbf{M}^{1}$ \\ and Müjde Kuş $\mathbf{M}^{1}$ \\ ${ }^{1}$ Department of Dermatology, Kahramanmaraş Sütçü İmam University, Turkey \\ ${ }^{2}$ Infectious Diseases and Clinical Microbiology, Kahramanmaraş Sütçü İmam University, Turkey
}

*Corresponding author: Hülya Nazık, Dermatology Department, Kahramanmaraş Sütçü İmam University, Turkey, Tel: 05055019162; Email: dr.hulyagul@hotmail.com

\section{Clinical Note \\ Volume 6 Issue 1}

Received Date: February 01, 2021

Published Date: February 12, 2021

DOI: $10.23880 /$ cdoaj-16000230

\section{Clinical Note}

Coronavirus infection is still being investigated by the physicians and healthcare professionals, and a new aspect about the disease stands out every day. The prominent aspects in the diagnosis and follow-up of the disease are followed with interest. Recently, the image of the fluorescence which is detected on the nails of patients with coronavirus under ultraviolet A (UVA) lamps has been viewed with interest by the society. In our dermatology clinic, we examined the hair and nails of the patients infected by the virus with wood's lamp.
We observed that lunula of all nails of the patients fluoresce glossy white and hair of the scalp fluoresce green. Fluorescence, detected in in both regions, was in more distal parts of the affected area in patients who had infection earlier, and was in more proximal parts in patients who had it later (Figure 1). When we searched the literature, we found studies supporting that this condition is related to Favipiravir used in the treatment of coronavirus infection. Thereupon, we examined the nails and hair of patients who had coronavirus infection and had a positive PCR test, but did not receive Favipiravir or any other treatment because they were asymptomatic and we observed that fluorescence was not detected in these patients.
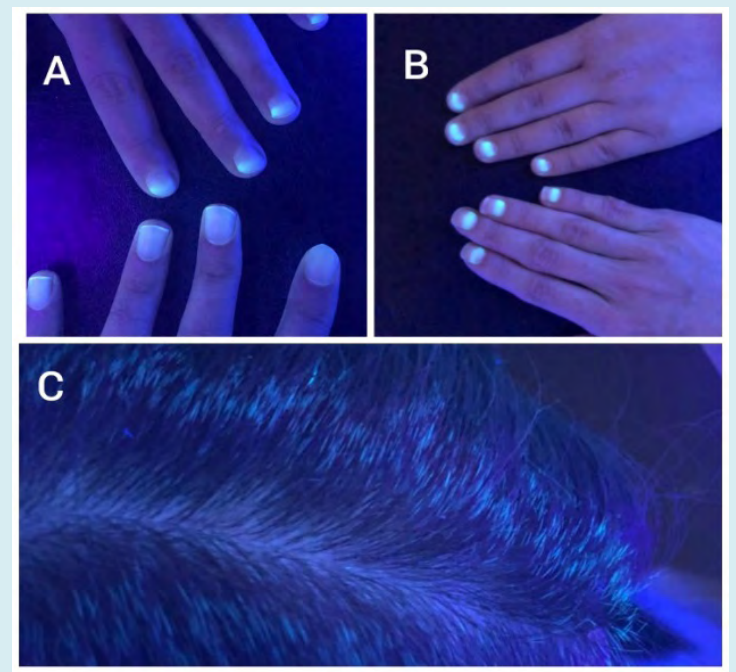

Figure 1: The images of the fluorescence taken by wood light examination on hair and nails associated with the use of Favipiravir.

A: Comparison of the nail of the patient using Favipiravir and the patient not using it.

B: Comparison of fluorescence obtained from patients who had used Favipiravir recently and patients who had it earlier.

C: Green fluoresce detected $1.5-2 \mathrm{~cm}$ distal to the hair. 


\section{Clinical Dermatology Open Access Journal}

According to the report published by the medicines and medical devices agency in 2014, it has been reported that the drug which has Favipiravir, an antiviral,as active ingredient, contains Titanium dioxide. Pale yellow or yellow fur, nails, or foot pads have been observed in various toxicity studies in mice, rats, and dogs. It has been observed that these colored areas fluoresce under ultraviolet light [1].

Titanium compounds such as dioxide, salicylate and tannate are used as an important ingredient in many pharmaceutical and cosmetic products nowadays. Titanium dioxide is the most important industrial compound of titanium. Titanium dioxide is also a food additive with international food code E-171, which is included in the composition of many foods or medicines owing to its moisture retaining and coloring properties. In recent years, it has been included in sunscreens due to its ability to reflect light [2].

Titanium dioxide participates in the structure of drugs as a metallic nanoparticle. Metallic nanoparticles provide opportunities such as targeted drug transport and increasing drug permeability or bypassing first pass metabolism [3].

These materials are cleaned according to their size. Small particles are quickly cleared by renal excretion. Those larger than $30 \mathrm{~nm}$ are cleared by macrophages that act as phagocytotic cleaners in the liver and spleen [4]. However, although some of the metallic nanoparticles used in drug transport are inert and biocompatible, they can be retained in the body after administration of the drug and this may cause toxicity [3].

As a result, it was concluded that Titanium dioxide, which is in the structure of Favipiravir that is frequently used in the treatment of coronavirus infection, is sequestered in keratinized hair and nail structures and it fluoresce under UVA lamps due to its ability to reflect light.

\section{References}

1. Report on the Deliberation Results (avigan tablet 200 mg), March 4, 2014 Evaluation and Licensing Division, Pharmaceutical and Food Safety Bureau Ministry of Health, Labour and Welfare.

2. Kaplan A, Çiftçi GA, Kutlu HM (2017) Eskişehir teknik univ. bilim teknol. derg. yaşam bilim. Biyoteknol 6(1): 3854.

3. Uyanıkgil EÖÇ, Salmanoğlu DS (2020) Targeting of metallic nanoparticles. Ege Journal of Medicine 59(1): 71-81.

4. Malam Y, Loizidou M, Seifalian AM (2009) Liposomes and nanoparticles:nanosized vehicles for drug delivery in cancer. Trends in Pharmacological Sciences 30(11): 592-599. 